\title{
CIVILIDAD A LA MEXICANA. LECTURAS DE LA HISTORIA ANTIGUA DE MÉXICO DE FRANCISCO CLAVIJERO EN LA PRENSA VIRREINAL DE BUENOS AIRES (1801)
}

\author{
MEXICAN CIVILITY. \\ READINGS OF THE HISTORIA ANTIGUA DE MÉXICO \\ BY FRANCISCO CLAVIJERO IN THE VICEREGAL \\ PRESS OF BUENOS AIRES (1801)
}

\author{
Matías Maggio-Ramírez \\ Universidad Nacional de Tres de Febrero \\ mmramirez@untref.edu.ar
}

\begin{abstract}
Resumen: La Storia antica del Messico de Francisco Javier Clavijero circuló en su edición italiana por las principales ciudades de América a finales del siglo xvin y principios del xıx. A partir de su presencia en el Telégrafo Mercantil, Rural, Político, Económico e Historiográfico del Río de la Plata, se analizó su difusión y apropiación. A pesar de los inconvenientes que tuvo la obra de Clavijero para su edición al castellano, se publicó en Buenos Aires una traducción local. La obra fue leída como una reivindicación americana, en el marco del proyecto ilustrado de civilización de las costumbres que la élite criolla fomentó mediante la prensa.
\end{abstract}

Palabras claves: identidad; civilidad; Francisco Javier Clavijero; periódicos del siglo xIx; Telégrafo Mercantil.

Abstract: The Storia antica del Messico by Francisco Javier Clavijero circulated in its Italian edition in the main cities of America in the late eighteenth and early nineteenth centuries. The diffusion and appropriation of its ideas are reflected in the Telégrafo Mercantil, Rural, Político, Económico e Historiográfico del Río de la Plata. In spite of the problems that made it difficult for the work of Clavijero to be published in Spanish, a local translation was published in Buenos Aires. The work was read as a vindication of America within the framework of the ideas of the Enlightenment about civilized society that the Creole elite fomented in the press.

Keywords: identity; civility; Francisco Javier Clavijero; newspapers

from the $19^{\text {th }}$ century; Telégrafo Mercantil.

Recepción: 30 de junio de 2017; aceptación: 19 de febrero de 2018.

D.R. () 2019. Nueva Revista de Filología Hispánica

Licencia Creative Commons Attribution-NonCommercial (CC BY-NC) 4.0 International 
INTRODUCGIÓN*

En dos oportunidades se ocupó Alfonso Reyes (1995, pp. 370380) del Telégrafo Mercantil, Rural, Político, Económico e Historiográfico del Río de la Plata en sus columnas de El Nacional. Sobre el editor del periódico, no dudó en calificarlo como "escritor medianejo", pero aun así destacó

...lo que hoy llamaríamos "el intercambio cultural hispanoamericano" [que] aletea tímidamente, como cuando se copian páginas de Clavijero sobre la educación entre los antiguos mexicanos ("Lecciones de un padre a su hijo", Historia antigua de México, por el Abate D. Francisco Xavier Clavijero, Cesena, 1780, II, lib. 7, en los números del 13 de mayo y 18 de julio de 1801).

La traducción al castellano de los textos de Clavijero no fue un gesto inocente del editor del periódico, ya que se insertó en su cruzada por modificar las costumbres de sus lectores -al punto que desde el mismo "Análisis" del Telégrafo Mercantil (1914) se intentaba civilizar a los porteños para que Buenos Aires no fuera "el fiero lunar de las provincias cultas"-, a la vez que abrió la puerta para la reivindicación americana contra la historia natural y moral europea de finales del siglo XVIII.

El periódico, que comandó el publicista extremeño Francisco Cabello y Mesa, apuntaba a la dulcificación de las pasiones de sus lectores para que estuvieran a la par de las ciudades metropolitanas. La crítica de costumbres fue uno de los pilares en la edificación de los "códigos de respetabilidad y distinción basados en el buen gusto, la elegancia discreta, la moderación, el agrado, el comportamiento civil y el intercambio social en cafés, tertulias y conversaciones", y se reproducía en la prensa a través del diálogo (Bolufer 2014, p. 2).

A las críticas que los lectores del periódico hicieron a los eruditos europeos se sumaron los textos de Clavijero como cuña de la crítica "patriótica" que desde el exilio hicieron los jesuitas americanos a las posturas de los filósofos de gabinete, como

* El presente artículo tiene como punto de partida la tesis doctoral Civilidad imaginada. La construcción de la civilidad como signo identitario en la prensa tardocolonial porteña. Un análisis del "Telégrafo Mercantil, Rural, Político, Económico e Historiográfico del Río de la Plata" y del "Semanario de Agricultura, Industria y Comercio" entre 1801-1803, defendida en la Facultad de Ciencias Sociales de la Universidad de Buenos Aires en agosto de 2016. 
Cornelius de Pauw, Georges Louis Leclerc (conde de Buffon), Noël-Antoine Pluche y William Robertson. Estos autores, entre otros, sólo conocían el territorio americano por la literatura de viajes, por lo que desde sus gabinetes de estudio argumentaron que la flora, la fauna y los hombres degeneraban en América respecto de la vara europea por la influencia del clima. Ante ese panorama distorsionado se recortaron los textos de Clavijero, cuya publicación en castellano fue entorpecida en España. Las lecciones de un padre y una madre a sus hijos se insertaban en la literatura didascálica europea para demostrar la civilidad de los americanos en oposición a la literatura europea de los eruditos de gabinete. Esas lecciones se tradujeron por primera vez al castellano en la prensa porteña como parte de la apuesta por la civilización de las costumbres en el joven virreinato del Río de la Plata.

\section{La RECEPCIÓN DE la STORIA ANTICA DEL MESSICO}

Enviado por Carlos III como visitador del virreinato de Nueva España, José de Gálvez y Gallardo llegó a México en 1765. Entre las disposiciones reales que llevó consigo se incluía aquella que expulsaba a los jesuitas de los dominios del monarca Borbón. En la madrugada del 25 de junio de 1767, en cumplimiento de la Real Pragmática, los miembros de la Compañía de Jesús de todo el territorio americano bajo el dominio español fueron expulsados; los religiosos residentes en Guadalajara, arrestados y trasladados primero a la capital novohispana y luego al puerto de Veracruz. Mientras esperaban los barcos que los llevarían a Italia, en el presidio murieron 34 jesuitas de fiebre amarilla. Veracruz, la ciudad donde nació Francisco Clavijero, fue la misma que lo vio partir el 25 de octubre de 1767 en el paquebote Nuestra Señora del Rosario de Torrentegui. El jesuita veracruzano se instaló primero en Ferrara, entre octubre de 1768 y junio de 1770, donde trabó amistad con el conde Aquiles Crispi y su hijo Benedicto, quienes le permitieron consultar su biblioteca (Trabulse 1988). Luego se trasladó a Bolonia, donde comenzó a redactar la Historia antigua de México en español, cuyo manuscrito se había dado por perdido hasta 1945, cuando se publicó en una edición al cuidado del jesuita mexicano Mariano Cuevas, aunque sin las disertaciones, escritas, según se cree, directamente en italiano. 
El propio Francisco Clavijero dio noticia de que su Historia antigua de México se había escrito en castellano, pero que "inducido después por algunos literatos italianos, que se mostraban deseosos de leerla en su propio idioma, tom [ó] el nuevo y laborioso empeño de hacer la traducción" (Clavijero 1826, p. xii). La Storia se publicó en italiano en cuatro volúmenes, los tres primeros en 1780, y el último, que contenía sus disertaciones, al año siguiente. En la corte española se conspiró para evitar su publicación en español, una vez editada la Historia en Cesena. El abate Lorenzo Hervás y Panduro, en su Historia de la vida del hombre, escribió sobre la obra de Clavijero en una nota al pie para informar a sus lectores que

Esta historia se ha traducido en alemán, inglés y francés. El autor la escribió primeramente en español, y después en italiano; por lo que se debe tener por texto original su historia española, que antes de su muerte acaecida a 2 de abril de 1787 envió a Madrid para que se imprimiese. El autor un año antes de morir me avisó que tenía casi concluida la historia geográfica y eclesiástica de México, que a instancias mías había escrito (1789, t. 2, Parte primera, p. 243, n. 2).

El manuscrito español preparado para la imprenta no tuvo mayor suerte. El impresor madrileño Antonio de Sancha presentó ante el Consejo de Indias, con fecha del 22 de abril de 1785, una "solicitud de licencia para la publicación de los tomos $1^{\circ}$ y $2^{\circ}$ que Clavijero había traducido del italiano y le remitía al intento. Los fiscales del Consejo manifestaron que el libro tenía pasajes injuriosos a los españoles" (Medina 1958, p. 28). En septiembre de 1784, meses antes de la petición de Sancha al Consejo de Indias, el Ministro de Indias, José de Gálvez y Gallardo, había solicitado examinar la Historia de Clavijero, con el argumento de que el rey Carlos III se encontraba personalmente interesado, pues había sido informado recientemente de que el texto del jesuita era despectivo hacia España y su conquista de América (Wauchope 1976). El interés en la obra de Clavijero por parte del rey y su ministro surgió de la carta que el jesuita español Ramón Diosdado Caballero, exiliado en Roma, escribió a José de Gálvez el 5 de agosto de 1784, en que le advertía de la naturaleza escandalosa de la Storia, la cual ya había leído en italiano.

El jesuita catalán Ramón Diosdado luchó por defender el régimen colonial español en América, especialmente en su obra 
Excelencia de la América española sobre las extranjeras, decidida con los hechos. Logró desbaratar los planes de impresión de la Storia de Clavijero, porque consideraba que

[el] criollo describía un pasado amerindio glorioso, pero no decía nada del papel de España en la pacificación de los amerindios con voraces apetitos por carne humana... Diosdado sostenía que las visiones gloriosas del pasado indígena por fuerza implicaban una crítica de España (Cañizares Esguerra 2007, pp. 324-327).

En su obra Breve examen acerca de los primeros tiempos del arte tipográfico en España, Diosdado demostró ante los italianos que ninguna nación tenía tantas imprentas en sus territorios entre 1451 y 1500 como España; es decir, la glorificación de la patria era tópico recurrente en su escritura. La traducción al castellano del Breve examen, a cargo de Vicente Fontán, se publicó en 1865. Allí se incluyó una breve biografía del autor escrita por Félix Torres Amat, la cual permitió saber algo más de la conjura contra Clavijero. Con espíritu ibérico, el responsable de la semblanza sostuvo que Diosdado ${ }^{1}$ escribió unas Observaciones americanas; y suplemento crítico de la historia de Méjico etc., en 3 tomos en $4^{\circ}$, para corregir la Historia de Clavijero. Se las envió a José Gálvez con la autorización para darlas a la imprenta, pero bajo el seudónimo Philiberi Parripalma. No sólo cifraba frente al veracruzano su amor por España en su seudónimo, sino que también recordaba su antigua patria chica, ya que había nacido en Palma, Islas Baleares. Si bien tuvo el visto bueno para la impresión de sus Observaciones, se presume que éstas no llegaron a la imprenta a causa de la muerte de Gálvez.

1 Cabe señalar sobre la conjura de Diosdado contra Clavijero que CAÑIZARES EsGUerRA (2007, p. 326) sostiene la imposibilidad de acceder a la fuente manuscrita en el Archivo de Indias, ya que "[Charles E.] Ronan basó su estudio de la campaña de Diosdado en gran medida en información obtenida en la década de 1960 en el Archivo de Indias bajo la firma de Patronato 296. En 1997, no pude encontrar ninguno de esos documentos bajo Patronato 296". WaUchope (1976, p. 283) informa que las líneas que Diosdado escribe a Gálvez en el comienzo de su escalada contra el veracruzano se encuentran en la siguiente signatura: "MS, Sobre la historia de Clavijero. El Consejo de Indias pleno de tres salas, Madrid, 21 de octubre de 1785, AGI, Patronato 196, fol. 46 v." Mientras se revisaba el artículo para su impresión, se halló el documento digitalizado en la plataforma http://pares.mcu.es, bajo el código de referencia ES.41091.AGI/29.4.3//PATRONATO,296A,R.1. 
En marzo de 1787, un mes antes de la muerte de Clavijero, el Consejo de Indias aprobó la edición de su Historia con la advertencia de que se siguieran las recomendaciones que el censor Juan Bautista Muñoz había hecho a partir de la obra de Diosdado, de la que también había sido examinador. Se pasó “...todo en informe a don Francisco de Cerdá y Rico, quien murió sin evacuar su informe, y después de otras diligencias y acuerdos quedó al fin el expediente sin resolver y el libro por publicar" (Medina 1958).

Diosdado estaba en contra de la glorificación del pasado mexicano precolombino que se hacía en la obra de Clavijero, quien presentaba a los amerindios apegados a los dictados de la moral. Por el contrario, Diosdado tenía la convicción de que los americanos eran pueblos salvajes y de que había sido España la responsable de pacificar sus "voraces apetitos de carne humana", lo que les habría permitido civilizarse en relación con sus antepasados. Entre las críticas del catalán a ciertas declaraciones que le eran imposibles de digerir, se encontraba la comparación de Clavijero entre los griegos, descendientes de Platón y Pericles, que padecían el Imperio otomano, y los mexicanos, hundidos en la miseria por los españoles. Que el pasado de esplendor se diluyera en el tiempo a causa de la Conquista fue un punto inaceptable para Diosdado (Brading 2004, p. 490).

A pesar de la accidentada publicación en España, la obra de Clavijero tuvo amplia circulación en Europa. Por ejemplo, el venezolano independentista Francisco de Miranda -quien, por cierto, criticó severamente la obra del abate Raynal, al igual que Clavijero- compró en Roma la Storia para hacerla traducir en Inglaterra. La traducción al inglés de Charles Cullen, que contó con la ayuda del propio Clavijero, se editó en Londres en 1787 en dos volúmenes in-quarto “...y se reimprimió varias veces en [Estados Unidos de] América (la primera en Filadelfia, 1804, y luego en 1806, 1807 y 1817)" (Gerbi 1960, p. 176). La traducción inglesa dio pie a la elaboración de varias reseñas en la prensa ${ }^{2}$. Un comentario anónimo en London Review "declaró que la historia de Clavijero no tenía valor" y que "la buena historia... era la historia moderna europea, capaz de dar leccio-

${ }^{2}$ Las publicaciones en inglés que reseñaron la traducción fueron demasiadas como para dar cuenta de todas ellas en este trabajo; más bien, ameritan un estudio detallado aparte que ofrezca pormenores sobre la recepción de la obra de Clavijero entre los contemporáneos anglófonos. 
nes de moral al presente. La historia de los aztecas involucraba bárbaros y no tenía ninguna lección que enseñar" (Cañizares Esguerra 2007, p. 117). El 13 de octubre de 1788, el periódico español editado por Cristóbal Cladera, El Espíritu de los Mejores Diarios Literarios que se Publican en Europa, dio a la luz una traducción de la crítica del British Register ${ }^{3}$, en que se calificaba la obra como la "más probable y correcta de cuantas se han escrito" (Trabulse 1988) y se afirmaba que es “...extensa, interesante y al paso que nos manifiesta los progresos de la civilización de los Mexicanos rodeados por todas partes de salvages, nos llena de admiración. ¿Qué lástima que esta obra esté sembrada de ideas supersticiosas!" (Trabulse 1988). Y a propósito del último tomo de la Storia, que contiene las disertaciones contra De Pauw, Buffon y Raynal, no concede demasiado crédito al veracruzano, porque "si M. Robertson humilló demasiado la inteligencia de los Americanos, quizás ha pecado en el extremo contrario el Abate Clavijero".

La traducción alemana se realizó a partir de la versión inglesa en 1789-1790, en Leipzig. Pronto se tradujo al francés, pero en castellano, la Historia seguía sin poder leerse. La obra de Clavijero en italiano circuló en América y fue leída en la prensa ilustrada tanto en México como en Lima. Se intuían los problemas para su publicación en castellano, pero aun así fue citada con ahínco como fuente de autoridad. José Antonio Alzate Ramírez conoció la obra del jesuita en 1784, y después de una lectura minuciosa, comenzó a anotarla y a asentir o a discutir con ella en un diálogo íntimo (Moreno 1976, p. 80). En la Nueva España se hicieron algunos intentos por traducir y publicar al jesuita, pero no llegaron a buen puerto en ninguna de las orillas del Atlántico ${ }^{4}$.

Alzate Ramírez, en la Gaceta de Literatura de México del 25 de junio de 1789, transcribió a sus lectores un fragmento de la correspondencia que mantuvo con el impresor Antonio de Sancha. Para negar "un susurro muy vulgar de estar prohibida la

${ }^{3}$ Lamentablemente, no fue posible dar con algún ejemplar de la reseña en inglés, con la cual se habría podido comparar la traducción que publica Cladera y, en consecuencia, rastrear si en ésta hubo algún agregado por parte del español.

${ }^{4}$ En México, la obra del jesuita tuvo una temprana traducción del "toscano al castellano" hecha por Diego Troncoso y Buenvecino, que, junto con las notas de Alzate, se conserva bajo la signatura 1976 en el Departamento de Manuscritos de la Biblioteca Nacional de México (Moreno 1972, p. 365). 
obra del insigne megicano", Alzate reprodujo la respuesta de Sancha:

Es cierto que tengo ánimo de imprimir la historia escrita por D. Francisco Javier Clavijero, y estaría impresa, a no haberla impedido una sangrienta crítica hecha contra ella por un americano, también de los expulsos, llamado un tal Diosdado, quien la remitió al ministro de Indias marqués de Sonora, y éste al consejo para que se tuviese presente, para cuando se pidiese licencia por mí para la impresión del Clavijero, como efectivamente se ha hecho, y los señores fiscales, en vista de uno y otro, han dado su parecer de que es digna de publicarse la expresada obra de Clavijero, y que la crítica se dirigía más bien a la persona que no a la obra, y que se debía despreciar, y me parece que en breve tendré la licencia del consejo para hacer la impresión que será de igual tamaño y papel que la historia de México de Solís que he publicado, aunque el carácter será un grado menor y en dos tomos iguales; las láminas procuraré igualmente vayan bien hechas y dibujadas mejor que la edición publicada en italiano en cuatro tomos en cuarto (Gaceta 1831, t. 1, p. 159).

A pesar de los buenos oficios, la publicación no se llevó a cabo, pero la obra tuvo una circulación fragmentaria en la prensa. En la Gaceta de Alzate, la Storia antica del Messico fue citada y transcripta en italiano para marcar la fidelidad de la fuente y por el temor a la acusación de plagio. El editor invocaba al lector: "léalo V. en italiano, para que no me acuse de falsario" (Gaceta de Literatura, 21 de marzo de 1789). La obra de Clavijero fue referencia de autoridad siempre que se trató en la Gaceta temas tan dispares como la flora o la arquitectura autóctonas. Pero, principalmente, la reivindicación americana no se dejó de lado ${ }^{5}$. Para desmentir las aseveraciones de los "pawnos", en alusión a los lectores y seguidores de Cornelius de Pauw, en una nota al pie de la Gaceta del 19 de julio de 1790 se sigue la reflexión del sabio Clavijero respecto a que "no debemos infe-

${ }^{5}$ En sus notas manuscritas, Alzate, con mucho más ímpetu que Clavijero, arremete contra los españoles; en la 135, por ejemplo, sostuvo sin cortapisas que si un indio "se dedica al estudio lo miran el maestro y condiscípulos como un ser inferior, tratándolo con tal desprecio que le obligan a desertar. La manía introducida de que para que estudien han de ir vestidos como los españoles impide el cultivo de las letras a muchos. ¿ ¿Si sus padres apenas tienen qué comer, cómo podrán soportar el gasto de un vestuario costoso para los hijos que estudian?” (Moreno 1976, p. 91). 
rir lo que fueron los megicanos por lo que son; así como no se puede inferir lo que fueron las repúblicas de Atenas y Esparto por lo que son en el día. Los grandes hombres Filipo, Alejandro, Aristóteles, Licurgo, Solón, Demóstenes, por lo que se observa respecto a los habitantes de la Grecia moderna" (Gaceta 1831, t. 1, p. 401) ${ }^{6}$. También se encontró citada la Storia en la Gaceta del 16 de agosto de 1791, cuando se discutió sobre el significado de la Piedra del Sol hallada en el Zócalo un año antes. El corresponsal ilustrado firmó su artículo con las iniciales E.F.D.R.H.P.D.N. y no tuvo pudor en reconocer que su escrito se valió de la obra del "verdaderamente erudito" Clavijero.

En el Mercurio Peruano del 21 de noviembre de 1793, el erudito José Manuel Bermúdez publicó su "Discurso sobre la utilidad e importancia de la lengua general del Perú", donde daba cuenta de la recepción de la Storia cuando escribió que "México se gloria de haber producido un Clavigero investigador profundo de sus antigüedades, las que sacó del olvido con pasmo y admiración del orbe literario" (Clément 1998, p. 260). Al sur de los antiguos dominios limeños, en la sede virreinal de Buenos Aires, se publicó en el Telégrafo Mercantil, en castellano, las "Lecciones...", aunque sin imaginar que cuestionaban la lectura realizada en el Consejo de Indias a partir de las Observaciones de Diosdado. A pesar de la censura virreinal, la obra de Clavijero se conoció fragmentariamente en castellano en la sede del nuevo virreinato del Río de la Plata en 1801. Luego, en 1826, gracias a los exiliados españoles en Londres, la Historia salió de la imprenta de Rudolph Ackermann traducida por José Joaquín Mora.

\section{LAS LECCIONES Y LA REIVINDICACIÓN AMERICANA}

La pronta traducción que tuvo la Storia dio origen a reseñas como la que se publicó en The Monthly Review, or, Literary Journal en 1787. En el minucioso comentario de cada libro en los que se divide la Storia se destacó la educación moral de los mexica-

${ }^{6}$ La nota 139 de Alzate a la obra de Clavijero, recopilada por MoReno (1976, p. 91), retomó estos argumentos: "Según algunos viajeros los griegos modernos a pesar del ignorante poder otomano aún mantienen algunos caracteres de los antiguos. Los indios modernos en nada se parecen a sus antepasados. Los libres, sin instrucción y viciados y los gañanes sin tiempo, porque todo lo emplean en servir a sus tiranos, apenas les bastan las luces naturales para conocer que son hombres". 
nos y, especialmente, la exhortación de un padre a su hijo, que catorce años después fue traducida del italiano al español en el Telégrafo Mercantil ${ }^{7}$. La decisión de reproducir un fragmento de la lección de un padre a su hijo en la publicación inglesa fue una estrategia discursiva que tenía por finalidad incidir en la disputa religiosa contra el catolicismo. Al llamar a los españoles misioneros del Papa y asesinos sin remordimientos, no sólo se criticaba la Conquista, sino que se ponía en evidencia la barbarie que había conllevado. En la prensa inglesa, las lecciones de los mexicanos a sus hijos fueron leídas como signo de civilidad que se contraponía con el proceder de los españoles durante la Conquista. En la Storia del jesuita veracruzano, se invirtieron los términos de la historia. Los bárbaros no eran los mexicanos, sino los españoles. El periodismo inglés utilizó a Clavijero para anudar la barbarie española con una cara del prisma del catolicismo, por lo que sirvió para atizar el viejo lugar común que se articulaba en torno a la "leyenda negra española". Uno de sus orígenes posibles se podría rastrear en el siglo XVI con la rebelión de los Países Bajos. La brutalidad de España en América y otros territorios fue propagada, por ejemplo, con la iconografía de Teodoro de Bry o con el libro Le miroir de la cruelle et horrible tyrannie espagnole perpétrée au Pays-Bas par le tyran duc de Albe et aultres commandeurs de par le roy Philippe le deuxième, editado por Johannes Cloppenburg, donde quedaba de manifiesto la crueldad española tanto en los dominios americanos como en los Países Bajos.

Al narrar la historia de México y dedicar un apartado a la educación de sus antiguos habitantes, el jesuita discutía con los eruditos europeos que, como Cornelius de $\mathrm{Pauw}^{8}$, escribieron

7 "The seventh book chiefly treats of the manners of the people. Their mode of education is particularly described, and an account is given of their public feminaries of learning. The best information we can afford our Readers of this people, their morality, and their method of educating children, is by transcribing the following exhortation of a Mexican to his son" (The Monthly Review, or, Literary Journal, vol. 76, p. 636).

8 Clavijero (1826) escribió sin ningún pudor, en el comienzo de sus Disertaciones, la opinión que le merece De Pauw: “¡Cuántos, al leer, por ejemplo, las investigaciones de Mr. Paw no se llenarán la cabeza de ideas disparatadas, y contrarias a lo que yo digo en mi Historia! Aquel escritor es un filósofo a la moda; hombre erudito, en ciertas materias en que más le convendría ser ignorante, o callar a lo menos; realza sus discursos con bufonadas, y maledicencia, ridiculizando todo lo más sagrado que se venera en la iglesia de Dios, y mordiendo a cuantos se le presentan, sin ningún respeto a 
sobre América. En las disertaciones, que ocuparon el cuarto tomo de la Storia, Clavijero buscó contrarrestar "el objeto de la obra de Mr. de Paw [que] es persuadir al mundo que en América la naturaleza ha degenerado enteramente en los elementos, en las plantas, en los animales y en los hombres". Clavijero cuestionaba el parecer de De Pauw acerca de los americanos. El erudito de gabinete sostenía que apenas se diferenciaban de las bestias, por lo que era necesario contraponer a ese argumento la civilidad de sus antiguas costumbres. El jesuita resumió la postura de su antagonista ante los americanos:

Los hombres apenas se diferenciaban de las bestias si no en la figura, aun en ésta se echaban de ver muchas trazas de degeneración; el color aceitunado, la cabeza dura, y con pocos, y gruesos cabellos, y todo el cuerpo privado enteramente de pelo. Son feos, débiles, y sujetos a muchas enfermedades extravagantes, ocasionadas por la insalubridad del clima. Pero por imperfectos que sean sus cuerpos, aún lo son mucho más sus almas. Son tan faltos de memoria, que no se acuerdan hoy de lo que hicieron ayer. No reflexionan, ni coordinan sus ideas, ni son capaces de mejorarlas, ni de pensar, porque los humores de sus cerebros son gruesos y viscosos. Su voluntad es insensible a los estímulos del amor, y a los de las demás pasiones. Su pereza los tiene sumergidos en la imbecilidad de la vida salvaje... Sus vicios morales corresponden a sus defectos físicos (Clavigero 1828, pp. 193-194).

La mirada lejana, mediada por narraciones de viajeros y por traducciones poco fieles, sin abandonar Europa, tuvo una respuesta encendida en la prosa de Clavijero durante su exilio italiano, donde intentó demostrar todo lo contrario a lo expuesto por De Pauw.

El inicio de la prensa porteña en 1801 tuvo no sólo la tarea de velar por la divulgación de los saberes útiles en favor de la "felicidad del pueblo", sino que apostó a la reivindicación identitaria en oposición a la narración que en Europa se realizaba sobre América. La independencia de Buenos Aires, a partir de 1776, de la antigua sede virreinal en Lima tuvo su correlato en una disputa literaria. En 1786 el clérigo limeño avecindado en Buenos Aires, Juan Manuel Fernández de Agüero y

la inocencia, y a la verdad; decide francamente, y en tono magistral, citando a cada paso a los escritores Americanos, y protestando que su obra es fruto de diez años de sudores". 
Echave, puso en duda la civilidad de los porteños porque un autor envió a imprimir unas décimas que consideraba poco logradas. Las respuestas no tardaron en llegar por parte de la élite letrada porteña en distintas formas literarias. Esta disputa menor continuó en el Telégrafo Mercantil cuando el limeño cuestionó el criterio del editor por publicar la "Oda al Paraná" de Manuel José de Lavardén, quien había sido uno de sus "enemigos" literarios. La prensa porteña evidenció la ausencia de tutela de Lima sobre Buenos Aires, porque sostenía que había llegado a la mayoría de edad (Maggio-Ramírez 2015). Además de ese gesto con que la élite letrada tomaba distancia de la antigua sede virreinal, se dejó de lado las lecturas europeas sobre América. Tanto el Telégrafo Mercantil (1801-1802) como el Semanario de Agricultura, Industria y Comercio (1802-1807) se concentraron en la crítica de costumbres y en el fomento de las "costumbres suaves" para contrarrestar la historia natural y moral europea, que presentaba a los americanos cercanos a la "barbarie" (Maggio-Ramírez 2017). La prensa fue entonces el espacio propicio para poner en evidencia las reglas de conducta "tenidas por civilizadas" y donde "se experimentaron fórmulas de intercambio social e interacción con el público" (Bolufer 2014). En ese marco, la recuperación de las lecciones de Clavijero implicaba una apuesta por visibilizar la urbanidad de los americanos del pasado, cuyas voces resonaban en los escritos de la ilustración hispánica sobre "buenas maneras", como los Dísticos de Catón traducidos y comentados por León de Arroyal.

\section{Las lecciones de Clavijero y la literatura DIDASCÁLICA}

Clavijero recuperó las lecciones que los padres transmitían a sus hijos entre los "antiguos mexicanos" gracias a que fueron escuchadas por los primeros "religiosos apostólicos que se dedicaron a su conversión, particularmente Toribio de Benavente, conocido como Motolinía, Olmos y Sahagún” (Telégrafo Mercantil 1914, p. 127 $)^{9}$. La mediación de la literatura didascálica americana tuvo como tamiz la tradición de la literatura cristiana medieval

${ }^{9}$ Clavijero se refiere al franciscano fray Toribio de Benavente, conocido como uno de los doce apóstoles de México, a fray Andrés de Olmos y al fraile Bernardino de Sahagún. 
y renacentista en la reescritura de los frailes españoles. En la cultura prehispánica, se hacía "énfasis en las buenas maneras, en el correcto comportamiento ante los demás, en el dominio de sí mismo, en el cuidado necesario, pero no excesivo, de la propia persona, en la educación sexual, en el hablar pulido y exquisito" (García Quintana 1974, p. 146). Al recuperar las exhortaciones de un padre a su hijo de la cultura náhuatl, desde las obras de los frailes Andrés de Olmos y de Bernardino de Sahagún, Clavijero incluyó una instancia más de mediación ${ }^{10}$. Las sentencias y enseñanzas que fueron tamizadas al pasar de la cultura oral a la escrita, habrían luego de ser reformuladas por el veracruzano en función de su defensa americana ante autores como el neerlandés De Pauw; con tal procedimiento, dotaba de civilidad a los pueblos originarios, cuyos descendientes eran presentados como bárbaros por los europeos. Clavijero, pues, se basó en los franciscanos que amalgamaron las exhortaciones con contenido cristiano para la evangelización. Se conservaba la forma retórica, pero los conceptos variaban (García Quintana 1974, p. 144). Fueron distintos cronistas quienes después de interpretarlas, reescribieron las lecciones conservando "el espíritu" de la traducción que realizó del náhuatl oral el fraile Andrés de Olmos. "Las Casas, Mendieta, Zorita, Torquemada y en el siglo XVIII, indirectamente, Clavijero" abrevaron en las exhortaciones recuperadas de la cultura oral por el fraile De Olmos (García Quintana 1974, p. 141).

La escritura de las lecciones exhibía una clara influencia de la literatura sapiencial europea, así como ecos de la Historia general de las cosas de Nueva España del fraile franciscano Bernardino de Sahagún ${ }^{11}$ y de la "Exhortación de los padres que así aconsejan, así instruyen a su hijo para que en forma

10 En la edición de finales del 1600, el fraile Juan Bautista tomó fragmentos de la obra de Andrés de Olmos, como la "Exhortación del padre al hijo”. Juan Bautista corrigió aspectos gramaticales y cambió sinónimos; también añadió "algunas frases que tienen el propósito muy claro de incluir conceptos cristianos, además de los que ya Olmos le había añadido" (GARCía Quintana 1974, p. 141). Es decir, la circulación de las exhortaciones de padres a hijos fue territorio fértil para que cada intérprete dejara sus huellas mixturadas con las de su antecesor.

${ }^{11}$ Clavijero (1826, p. 359) escribió que vio un ejemplar en "la librería del colegio de Jesuitas de la Puebla de los Ángeles”, pero el investigador José Luis Martínez (1981, p. xxii) sostiene que el jesuita veracruzano se refirió a Sahagún sin conocer la obra, "recogiendo datos de Vetancurt y del bibliógrafo" fray Juan de San Antonio, quien abordó la obra de Bernardino 
buena, recta se digne vivir", recopilada por el fraile Andrés de $\mathrm{Olmos}^{12}$. Mientras el primero dejaba las huellas de las idolatrías para conocerlas y así poder extirparlas, el segundo las suprimió e intercaló en su texto conceptos cristianos (García Quintana 1974, pp. 144-145) ${ }^{13}$. "Los consejos de un padre náhuatl a su hija”, recogidos por Sahagún e incorporados al Códice florentino en los folios 74v-84v (Weinberg 1995, p. 231), y la "Exhortación..." de Andrés de Olmos fueron insertos por Clavijero, principalmente en la lección de un padre a su hijo, en una larga tradición cultural de la literatura sapiencial que puso en contacto los huehuetlatolli ${ }^{14}$, en cuanto conversaciones o pláticas de

de Sahagún en su Biblioteca universal franciscana, publicada en Madrid en 1732-1733.

12 De los textos originales que el fraile De Olmos compiló, "sólo se ha conservado una pequeña muestra en la última parte de su Arte de la lengua mexica. Sin embargo, el misionero franciscano entregó además una traducción parcial de estas pláticas al oidor Zorita y a fray Bartolomé de las Casas, quienes la incluyeron en la Relación de los señores de la Nueva España y la Apologética historia de las Indias respectivamente. Habrían de perdurar estos huehuetlatolli romanzados en forma de libro gracias a la labor de fray Juan Bautista, quien recopiló, enmendó y acrecentó los textos de Olmos, y finalmente los publicó con el título Huehuetlatolli, que contiene las pláticas que los padres y madres hicieron a sus hijos y a sus hijas, y los señores a sus vasallos, todas llenas de doctrina moral y política (1600)" (RUIZ BAÑUls 2005, p. 383).

${ }^{13}$ La investigación de Josefina García Quintana (1974, p. 145) sostiene que la cristianización de las lecciones se puede comprobar cuando se comparan los diez mandamientos con fragmentos de la exhortación mediada por el fraile De Olmos.

14 El vocablo huehuetlatolli ha sido objeto de disputas entre eruditos mexicanos. Una de las líneas, sostenida por Josefina García Quintana y retomada por León Portilla, indicaba que el vocablo no sólo significaba las palabras que los viejos dirigían a los jóvenes, sino que la "antigua palabra" incluía "la sabia memoria de los ancianos, y que es más bien un término genérico dentro del cual caben incluso las arengas, los refranes, los proverbios, las salutaciones, los modos de hablar elegantes, y aun, ¿por qué no?, las oraciones propiciatorias, imprecatorias muchas, dirigidas a los dioses. Todo participa, en resumidas cuentas, de ese estilo tan ponderado ya desde los primeros contactos culturales de los españoles con los indígenas: florido, recargado, elegante, insistente, pleno de metáforas, elocuente y mágico que éstos utilizaban para las ocasiones solemnes e importantes" (GARCÍA QuINTANA 1974, pp. 139-144). En cambio, las investigaciones de SAlvador Díaz Cíntora (1995) indican que la definición anterior es equívoca por lo amplio de su espectro. Para el estudioso, huehuetlatolli significa "el discurso de los viejos, tomando esta palabra relativamente, en el sentido de que el padre es viejo en relación al hijo; son verba maiorum, palabras de los mayores... y hay que restringir, a lo que parece, en lugar de ampliar...”. En definitiva, para 
los ancianos, con los espejos de príncipes medievales, en que el soberano cristiano debía simbólicamente mirarse para guiar su actuación (Nogales Rincón 2006, p. 9).

La tradición europea fue pródiga en esta literatura, por ejemplo, en los libros de empresas renacentistas o en la emblemática barroca que cifraron una enseñanza en la combinación entre una imagen y un texto que se retroalimentaban semióticamente. Los consejos de un padre a su hijo, así como los de una madre a su hija, fueron tópicos usuales en la historia de la literatura didascálica a través de distintas manifestaciones literarias y métricas (González-Blanco García 2007). Entre las obras que gozaron de mayor fortuna, se encontraban los "Disticha Catonis, texto latino que cobrará vida propia dando lugar a un sinfín de traducciones, versiones e interpretaciones" (González-Blanco García 2007). Una de las versiones de los Dísticos de Catón fue comentada por Erasmo de Rotterdam (véase la ed. de 1997) y tuvo múltiples traducciones al castellano, como la que circuló en la España ilustrada, llevada a cabo en 1797 por León de Arroyal, quien incorporó un quinto libro dedicado a la educación de la mujer ${ }^{15}$.

Los dísticos comentados por Erasmo dejaron su marca en distintas obras literarias. Proverbios erasmianos pueden encontrarse tanto en el capítulo 62, "De los consejos que dio don Quijote a Sancho Panza antes que fuese a gobernar la ínsula, con otras cosas bien consideradas", de Don Quijote de la Mancha de Miguel de Cervantes (2004), como en las lecciones de Clavije-

Mignolo y Ebacher (1994, p. 23), el huehuetlatolli, en cuanto vehículo para la dirección de valores morales y sociales en la población indígena, "proveía a los frailes de un molde ya conocido, entendido y gustado por sus oyentes nahuas para la presentación de los conceptos de la nueva religión”, por lo cual se convirtió en herramienta idónea para llevar a cabo la enseñanza moral y doctrinal de la fe católica entre los naturales.

15 José Emilio Burucúa (2001, p. 14) reconoce con certeza que el estudio de los proverbios fue una pasión para Erasmo, quien "veía en esas frases sintéticas y densas de sentido, llegadas a su época desde los tiempos más remotos, la condensación estéticamente perfecta del saber de los antiguos... Erasmo decía: "Creyóselas emanadas del cielo: tanta era la autoridad que se les concedía... Se las grababa en el mármol, se las inscribía en los frontones de los templos, porque se los juzgaba merecedores de una memoria perdurable... Hay en estas paremias, sin duda, una nativa y genuina fuerza de verdad; porque si no fuera así, ¿cómo se explicaría que muchas veces una sola sentencia haya pasado a cien pueblos y que no haya muerto, ni siquiera envejecido, a través de tan largo discurso de siglos, que ni las mismas Pirámides pudieron resistir?»". 
ro. La particularidad de la "Exortación de un Megicano a su hijo" es que en ella pudo hallarse la tradición medieval y renacentista de los dísticos de Catón, junto con la reescritura de los huehuetlatolli de Sahagún y De Olmos. Clavijero reinterpretó y purgó los textos de los frailes franciscanos de su poética concepción del mundo y centró su texto en una argumentación netamente deóntica instruccional desde el momento en que hay una distribución asimétrica del saber entre los interlocutores y tiene por fin lograr un cambio, modificar una conducta en el destinatario al seguir una instrucción formulada desde el deber ser. La cultura náhuatl, de este modo, fue labrada a partir de la literatura didascálica de tradición europea. Por ejemplo, se puede leer en el dístico catónico que se apela a la súplica a Dios; en el texto de Sahagún, el mismo proverbio se extiende:

He aquí tu oficio, lo que tendrás que hacer: durante la noche y durante el día, conságrate a las cosas de Dios, muchas veces piensa en el que es como la Noche y el Viento. Hazle súplicas, invócalo, llámalo, ruégale mucho cuando estés en el lugar donde duermes. Así se te hará gustoso el sueño (Weinberg 1995, p. 231).

En la lección de un padre a su hijo dada a conocer por Clavijero, la invocación de protección a la divinidad se envolvía con las siguientes palabras:

Hijo mío, le decía el padre, has salido a luz del vientre de tu madre, como el pollo del huevo, y creciendo como él, te preparas a volar por el mundo, sin que nos sea dado saber por cuánto tiempo nos concederá el cielo el goce de la piedra preciosa que en ti poseemos: pero sea el que fuere, procura tú vivir rectamente rogando continuamente a Dios que te ayude. Él te crió, y él te posee. Él es tu padre, y te ama más que yo: pon en él tus pensamientos, y dirígele día y noche tus suspiros (Telégrafo Mercantil 1914, p. 127).

Es decir, la escritura de Clavijero se anudó al corpus clásico de la literatura proverbial y sapiencial para que sus lectores pudieran hallar en la educación moral de los niños dieciochescos aquello que los unía con los antiguos americanos. La operación del veracruzano consistió en evitar el exotismo al que fue sometido el territorio americano y sus habitantes por parte de cronistas y filósofos ilustrados. Para acercar el pasado mexicano al presente de sus lectores, utilizó una estrategia propia de 
la literatura sapiencial medieval que ya habían adoptado Sahagún y De Olmos. La originalidad de una colección de sentencias "...radica en la configuración del nuevo «corpus» que se elabora, lo cual dará una intencionalidad y significación propia a la colección" (Bizzarri 1996). El propósito de las lecciones de Clavijero fue ofrecer "...la prueba más convincente de que «el imperio de la razón» no estaba limitado a Europa... El modo de educación de los jóvenes era la señal más segura de la cultura de un pueblo, y estos coloquios revelaban, sin duda, un alto nivel" (Brading 2003, p. 494).

\section{Las apropiaciones de Clavijero \\ EN EL TELÉGRAFO MERCANTIL}

Entre las lecturas que se hicieron de Clavijero casi inmediatamente después de la publicación de la primera lección, el 13 de mayo de 1801, se puede sumar el texto "Lecciones de un camilucho a su hijo", escrito en Canelones el 29 de julio y publicado en el Telégrafo el 26 de agosto de 1801 (Telégrafo Mercantil 1914, pp. 375-378). El escrito en clave local retomaba las lecciones de Clavijero para hacer hincapié en el fomento de las buenas costumbres, la moral cristiana y familiar. La gente de letras encontró en la prensa un canal de diálogo con sus pares en los distintos puntos cardinales del virreinato. Si bien las polémicas fueron escasas, no así las cartas de los suscriptores, como la que envió el abogado Eugenio del Portillo desde Oruro, en territorio del virreinato, donde se ponía en evidencia la circulación de la literatura instruccional ligada a las buenas costumbres:

...corren con mucha aceptación y crédito los dos tomitos del Sr. Rosell sobre La educación, conforme a los principios de la religión christiana, leyes y costumbres de la nación española; fuera de innumerables preciosas traducciones de las lenguas vulgares, asegurando el Abate Andrés que ya fastidian tantos libros de esta materia (Telégrafo Mercantil 1914, p. 443).

En ese marco, las lecciones a un camilucho se insertaron en su comienzo en la narrativa epistolar, propia del siglo XVIII, para luego, por medio de los adagios, dar las pautas del padre para el buen ejercicio del comercio. El camilucho confiaba en el pro- 
greso y en los frutos de su trabajo, porque "sin más discernimiento que el de un rústico campestre..., [no ha] dejado de buscar todos los medios capaces [del adelantamiento] de su hijo". Su sacrificio y privaciones le permitieron educar a su vástago con "menos trabajo material y de más adelantamiento" que el trabajo paterno. En un gesto que podría emparentarse con el de Emilio de Rousseau, el autor de la lección, que se esconde tras las iniciales M.A.F., presenta en el "rústico padre" la bondad y urbanidad con que entregaba a su hijo los consejos apropiados para enfrentarse en la ciudad al ejercicio del comercio. Le ruega a su hijo que se conserve puro y honrado a pesar de los "muchos bienes de fortuna que Dios te dé" y que recuerde sus orígenes humildes, porque "así serás estimado por todos". Las lecciones siguientes apuntan a educar en las artes del comprar barato y vender con beneficios, sin necesidad de caer en el contrabando, porque "tu ánimo vivirá inquieto como tu conciencia". También le aconseja que no comercie con bienes de primera necesidad, porque "las ganancias que de ellas te resulten no llegarán a tus hijos". Siguen luego los consejos para procurar que los criados y mozos de tienda o escritorio vivan bien y de acuerdo con la religión cristiana; que nunca sepan con certeza "ni la hora en que has de salir a pasear, ni cuándo podrás volver, porque así estarán con más cuidado"; que tampoco lleven cuentos y chismes de criados, por lo que también aconseja que aquellas "cosas que no quieres que se sepan, no las hables, ni en disfraz, delante de ellos". Dar buenos ejemplos a los empleados y vigilar sus conductas y diversiones era parte del deber de un buen comerciante, el cual tampoco habría de permitir que sus criados se juntasen con otros por ningún motivo.

La transmisión generacional es una constante en las lecciones, por lo que después de los consejos ligados al comercio y al trato de los empleados, el padre adoctrina a su hijo en los deberes de todo buen esposo y padre de familia, a propósito de lo cual le pide que se acuerde "de la educación que yo te he dado a ti, por que tú la mejores en lo posible, teniendo mejores proporciones que tuvo tu padre". La tensión de castas aparece también en las lecciones cuando se recomienda que los niños no se junten con criados esclavos, "porque con ellos no se aprenden cosas buenas". Sin embargo, tampoco es permisible que se reúnan con muchachos revoltosos, "ni con el pretexto de ser sus condiscípulos". El camilucho, preocupado por la educación de su descendencia, aconseja: si los niños "quisiesen entrar en colegio, 
consulta bien su gobierno y plan de estudios, para que después no te pese de haberlos separado de tu lado". La última advertencia es que salga de paseo siempre con la mujer e hijos, para evitar tener tertulia fuera de casa por las noches, porque dejar sola a la familia "suele ocasionar muchos daños irremediables".

Ambas lecciones, la de Clavijero y la del camilucho, se publicaron en el Telégrafo como manuales de urbanidad, ya que indicaban desde la manera idónea de comportarse en las interacciones sociales hasta los principios para dedicarse al comercio honesto. La literatura instruccional se coló en la prensa porque tenía como motivo la crítica de costumbres, que intentaban corregirse, ya fuera mediante papeles impresos, ya a través de la educación. Sobre esto, tanto en el Telégrafo como en el Semanario hubo una división tajante entre quienes aseguraban que la educación era más eficaz en el ámbito doméstico y quienes preferían la educación pública en las escuelas del rey.

El virrey de Croix, asentado en Lima, sostuvo tras la creación del virreinato del Río de la Plata que esa región "ha probado ser una colonia de meros comerciantes". A diferencia de otras ciudades americanas con tradición, nobleza y abolengo, en Buenos Aires el dinero era el signo de superioridad social, por lo cual los comerciantes tuvieron un papel preponderante. En las lecciones del camilucho, se destacó en las primeras líneas el sacrificio del padre para lograr la educación formal de su hijo, lo que implicaba un ideal de progreso y movilidad social ascendente. La ficción literaria que representaba el espíritu ilustrado se contrapone con la observación de Socolow acerca de que "solo existe un ejemplo de hijo criollo de artesanos que llegó a ser comerciante mayorista. Se podía hacer carrera únicamente si se era hijo de los comerciantes locales y a veces hijo de comerciantes minoristas". Además, para el ingreso en la carrera comercial, "se requería solo una educación elemental (primeras letras) y un aprendizaje de lectura, aritmética, escritura y contabilidad. Este requerimiento del alfabetismo impidió a los grupos más pobres de la sociedad española aspirar siquiera a ser aprendices" (Socolow 1978, p. 208). Por esta razón, los hijos de comerciantes porteños contaban con una ventaja respecto de los españoles que tenían una formación elemental. Los bonaerenses gozaban de "una educación secundaria completa y a veces hasta [de] estudios universitarios. El comerciante criollo tenía mejor nivel educacional o al menos era más culto que el inmigrante español" $(i d$.$) . La lección del camilucho era la con-$ 
tinuación en clave del discurso instruccional mercantil de las exhortaciones de Clavijero, así como lo fueron el artículo "Idea general del comercio de las Provincias del Río de la Plata" y la "Oda al comercio", que un anónimo lector envió al Telégrafo.

Las lecciones de Clavijero tuvieron como meta instruir a los lectores, tal como lo había propuesto Cabello y Mesa en el "Análisis" de su periódico. También fueron utilizadas como argumentos para cuestionar la opinión que los eruditos europeos, incluso españoles peninsulares, tenían sobre América. La redacción y la publicación de la lección de un camilucho a su hijo intervinieron en un tema caro a los intereses locales de una ciudad en expansión: las buenas prácticas comerciales. La lectura e interpretación de Clavijero en la banda oriental del Río de la Plata se hizo de un modo particular, toda vez que fomentaba en su ficción la movilidad social ascendente y la crítica del ocio, al tiempo que mantenía el statu quo de mujeres, niños y esclavos como forma de sostener la reproducción de la vida social de la burguesía en crecimiento.

\section{Conclusiones}

Lo que queda de manifiesto en la escritura de Clavijero es la acción política de su escritura que vincula la tradición mexicana a un clásico corpus de la literatura proverbial y sapiencial para que sus lectores, en lo que toca a la educación moral de los niños, encuentren aquello que los une con los antiguos americanos. La operación de Clavijero consistió en evitar el exotismo al que fue sometido el territorio americano y sus habitantes por parte de cronistas y filósofos ilustrados. Esa elección fue una apuesta historiográfica que entraba en tensión con la realizada por el rector de la Universidad de Edimburgo, Williams Robertson, en su Historia de América. Allí, el escocés escribió que "ni los mexicanos ni los peruanos tienen derecho de compararse con las naciones que merecen el nombre de civilizadas", tópico usual en la literatura antiamericanista -que, por cierto, reverdeció tras las reformas borbónicas-al que se enfrentó el veracruzano (Annino y Rojas 2008, p. 17). La opción historiográfica de Clavijero se apoyó en la erudición anticuaria, según Elías Trabulse (1988), ya que en su intento por alcanzar mayor objetividad e imparcialidad acudió a las fuentes primarias, de carácter literario, principalmente, así como también 
al análisis de documentos, inscripciones y monedas en archivos y bibliotecas. Para Trabulse, fue en México "donde recibió toda la «preceptiva» doxográfica y heurística y, lo que es más importante, fue también aquí donde se acercó a las fuentes primarias y secundarias de la antigüedad indiana que luego utilizaría en su obra histórica"; por ello, años más tarde, en los tiempos del destierro, lograría "una síntesis armoniosa entre la historia erudita y anticuaria practicada en México y la historia filosófica que ya dominaba los círculos intelectuales europeos". Para Cañizares Esguerra (2007, p. 408)

queda claro que Clavijero no descubrió ninguna fuente primaria nueva, sino más bien produjo interpretaciones nuevas del pasado mesoamericano... El análisis creativo que Clavijero realizó de las fuentes europeas e indígenas publicadas disponibles se hizo con un agudo ojo crítico atento a las técnicas humanísticas tradicionales de lectura.

En su erudición,

privilegió ciertos testimonios y excluyó otros, rechazando las pruebas ofrecidas por extranjeros, viajeros, colonos ambiciosos y plebeyos indígenas por ser poco confiables, pero tratando a los testimonios de los nobles nativos de principios de la Colonia y de los clérigos cultos con el mayor de los respetos.

Es Trabulse (1988) nuevamente quien sostiene que, para el veracruzano, la historia no era solamente erudición, sino resurrección del pasado, por lo que "sus lectores mexicanos de finales del siglo XVIII y principios del XIX encontraron en ella una visión histórica completa, coherente y magistralmente descrita del mundo prehispánico que estimuló sus sentimientos patrióticos y nacionalistas". Para Annino y Rojas (2008), el patriotismo criollo durante la época virreinal había logrado instalar una visión propia de la historia mexicana con total autonomía de la escritura histórica de la metrópolis. Este modelo, sostendrían los investigadores,

[es] de claro origen agustiniano, a diferencia del renacentista, no eran las conquistas las que fundaban las identidades colectivas sino los procesos de cristianización. De esta manera, la Nueva España fue insertada en el movimiento universal hacia la salvación de la humanidad, impulsado por la Divina Providencia, y 
sin la intermediación de España, una evidente reivindicación de autonomía identitaria y política dentro del marco de la monarquía católica (p. 14).

Así, los criollos pudieron pensarse a sí mismos como ciudadanos libres de una república cristiana y, a la vez, como súbditos del rey. Clavijero logró defender la tradición del patriotismo criollo con el andamiaje ilustrado del siglo XVIII. La cultura patriótica desarrolló, según Aninno y Rojas (2008, p. 13), "una práctica difícil y a primera vista paradójica: celebrar el pasado pero, al mismo tiempo, criticarlo para explicar los problemas del presente: celebrar la nación pero, al mismo tiempo, destacar sus fallas y sus incumplimientos". La defensa ocurrió en el exilio, en donde el reformismo ilustrado borbónico dejó su huella en el paso del "patriotismo barroco del siglo XVII [que] había defendido el derecho al autogobierno como si fuera un privilegio" al de finales del siglo xviII, en que "el problema fue transformar la historia agustiniana, salvífica, y exclusiva de la Nueva España, en la historia constitucional de una república cristiana libre y vinculada sensualmente a la monarquía" (Annino y Rojas 2008, p. 21). Sin embargo, ésta es historia aparte.

Los lectores también conocieron sus postulados a partir de las referencias que sobre el filósofo neerlandés se hicieron en los periódicos españoles que llegaban a Buenos Aires. En el Telégrafo, entre el 13 de mayo y el 18 de julio de 1801, fechas en que en el mismo periódico se publicó la traducción de dos fragmentos de la Storia antica del Messico, se incluyó, el 23 de mayo, concretamente, el artículo "Educación. Amados compatriotas", que en tres entregas reflexionó acerca de cómo la educación podría servir para fomentar la felicidad de la patria. El texto estaba firmado por "P.J.F.C.", iniciales que probablemente pertenezcan a Pedro Juan Fernández. Su propósito era apuntalar la educación pública como emblema de la razón para extirpar las costumbres erradas, los vicios y las supersticiones que se transmitían generacionalmente. Para el colaborador de Cabello y Mesa, la educación "privada o doméstica de que ha empezado a tratar el N. 13 del Telégrafo merece sin duda todo el cuidado de los padres de familia", por lo que destacaba la difusión de Clavijero en tiempos ilustrados, aunque sirviera para demostrar la "civilidad" de los pueblos "bárbaros" en el antiguo México (Telégrafo Mercantil 1914, p. 151). La propuesta de Clavijero, así como las críticas que mantiene a la obra de Cornelius De Pauw, evidenciaron 
que aún eran tema relevante para el lector porteño, marcado por las reformas borbónicas. Meses después de las lecciones, el 4 de octubre se publicó en el Telégrafo, bajo el seudónimo de Enio Tullio Grope, la lectura de Eugenio del Portillo sobre la traducción de los textos de Clavijero, que cuestiona, según se muestra en seguida, la verosimilitud del texto trasladado:

El rasgo sobre la educación de los Mexicanos pág. 98 es muy precioso; pero del Abate Clavigero que transmite tan sublime moral se puede hacer la crítica que algunos sabios han hecho de la historia de Solís, esto es, que tiene honores de poema (Telégrafo Mercantil 1914, p. 442).

La incorporación de los textos de Clavijero al ámbito letrado porteño se interpretó como oráculo de la civilidad, de la urbanidad y buenas costumbres, sin tener en cuenta la apuesta historiográfica; en otro extremo, se lo leyó en clave ficcional, en lo que respecta a los datos históricos, pero valorando lo instructivo de las lecciones.

El texto del Telégrafo, firmado por "P.J.F.C.", retomó la crítica de Clavijero a De Pauw al sostener que

con buenas casas de educación pública llegaremos a persuadir a el señor de Paw, y a otros como él, que somos tan hombres como los del antiguo continente. Sin más armas que la reforma de nuestra educación pública, quedarán combatidos cuantos pretenden degradarnos hasta de la racionalidad (Telégrafo Mercantil 1914, p. 152$)^{16}$.

La educación racional podría hacer frente a la tensión entre la civilidad y las lecturas que los filósofos de gabinete europeos realizaban de América. La degradación americana, según las miradas europeas, fue cuestionada desde la pluma del veracruzano como desde sus lectores porteños. La élite letrada bonaerense reivindicó una tradición que le era ajena porque escuchaba en ella los ecos de Erasmo y de la literatura didascálica ilustrada que volvió sobre sus escritos. Queda pendiente, entonces, rastrear las razones por las que se retomó y divulgó

${ }^{16}$ La obra Recherches philosophiques sur les américains ou mémoires intéressants pour servir á l'histoire de l'espèce humaine de Cornelius de Pauw no se publicó en castellano. Circuló en francés entre los lectores rioplatenses, al igual que su intervención en la Encyclopédie sobre América. 
la tradición de los antiguos mexicanos a la vez que se los cuestionaba por bárbaros.

\section{REFERENCIAS}

Annino, Antonio y Rafael Rojas 2008. La independencia: los libros de la patria, Centro de Investigación y Docencia Económicas-Fondo de Cultura Económica, México.

Bizzarri, Hugo O. 1996. "Difusión y abandono del Secretum secretorum en la tradición sapiencial castellana de los siglos XIII y xIv", Archives d'Histoire Doctrinale et Littéraire du Moyen Âge, 63, pp. 95-137.

Bolufer, Mónica 2014. "Civilizar las costumbres: el papel de la prensa periódica dieciochesca”, Bulletin of Spanish Studies, 91, 9/10, pp. 97-113, doi:10.1080/14753820.2014.962864.

Brading, David 2003. Orbe Indiano. De la monarquía católica a la república criolla, 1492-1867, Fondo de Cultura Económica, México.

BurucúA, José E. 2001. Corderos y elefantes: la sacralidad y la risa en la modernidad clásica, siglos XV a XVII, Miño y Dávila-Universidad de Buenos Aires, Madrid-Buenos Aires.

Cañizares Esguerra, Jorge 2007. Cómo escribir la historia del Nuevo Mundo. Historiografías, epistemologías e identidades en el mundo del Atlántico del siglo XVIII, Fondo de Cultura Económica, México.

Cervantes SaAvedra, Miguel de 2004. Don Quijote de la Mancha. Ed. F. Rico, Real Academia Española-Asociación de Academias de la Lengua Española, Madrid.

Clavigero, Francisco Saverio 1826-1828. Historia antigua de México, R. Ackermann, London [microfilm].

Clément, Jean-Pierre 1997. El Mercurio Peruano, 1790-1 795. T. 1: Estudio. T. 2: Antología, Vervuert-Iberoamericana, Frankfurt-Madrid.

Díaz Cíntora, Salvador (ed.) 1995. Huehuetlatolli: libro sexto del "Códice florentino”, Universidad Nacional Autónoma de México, México, http:// www.descolonizacion.unam.mx/pdf/publ_10.pdf [consultado el 29 de junio de 2017].

Diosdado Caballero, Ramón 1865. Breve examen acerca de los primeros tiempos del arte tipográfico en España, Oficina tipográfica del Hospicio, Madrid, http://archive.org/details/breveexamenacerc00cabauoft [consultado el 29 de junio de 2017].

Gacetas de literatura de México, por D. José Antonio Alzate Ramírez 1831. México, https://books.google.com.ar [consultado el 29 de junio de 2017].

García Quintana, Josefina 1974. "Exhortación de un padre a su hijo. Texto recogido por Andrés de Olmos", Estudios de Cultura Náhuatl, 11, pp. 137-182, http:/ /www.historicas.unam.mx/ publicaciones/ revistas/ nahuatl/pdf/ecn11/150.pdf [consultado el 29 de junio de 2017].

Gerbi, Antonello 1960. La disputa del Nuevo Mundo. Historia de una polémica, 1750-1900, Fondo de Cultura Económica, México. 
González-Blanco García, Elena 2007. "Las traducciones romances de los Disticha Catonis”, eHumanista, 9, pp. 20-82, htttp:/ /www.ehumanista. ucsb.edu [consultado el 29 de junio de 2017].

Hervás y Panduro, Lorenzo 1789. Historia de la vida del hombre. Pubertad y juventud del hombre, t. 2, parte I, Imprenta de Aznár, Madrid.

Maggio-Ramírez, Matías 2015. "El color de la palabra. Sobre la sátira de Manuel José de Lavardén y su polémica en el Telégrafo Mercantil (17861801)", Dieciocho, 38, 2, pp. 219-318.

Maggio-Ramírez, Matías 2017. "El Telégrafo Mercantil y el fomento de la civilidad. El nacimiento de la prensa de costumbres en el Buenos Aires virreinal", Historia y Comunicación Social, 22, 1, pp. 31-44, http://dx.doi. org/10.5209/HICS.55898.

Martínez, José Luis 1986. El libro en Hispanoamérica: origen y desarrollo, Fundación Germán Sánchez Ruipérez-Ediciones Pirámide, Madrid.

Medina, José Toribio 1958. Historia de la imprenta en los antiguos dominios españoles de América y Oceanía. T. 1, Fondo Histórico y Bibliográfico José Toribio Medina, Santiago, http:// www.cervantesvirtual.com/ servlet/ SirveObras/ [consultado el 29 de junio de 2017].

Mignolo, Walter D. y Colleen Ebacher 1994. "Alfabetización y literatura: los «huehuetlatolli» como ejemplo de la semiosis colonial”, en Conquista y contraconquista: la escritura del Nuevo Mundo (Actas del XXVIII Congreso Internacional de la Literatura Iberoamericana). Coords. Julio Ortega, José Amor y Vázquez y Rafael Olea Franco, El Colegio de México, México, pp. 21-30.

Moreno, Roberto 1972. "Las notas de Alzate a la Historia antigua de Clavijero", Estudios de Cultura Náhuatl, 10, pp. 359-392, http:/ / dialnet.unirioja.es/servlet/articulo?codigo $=3722907$ [consultado el 29 de junio de 2017].

Moreno, Roberto 1976. "Las notas de Alzate a la Historia antigua de Clavijero" (Addenda), Estudios de Cultura Náhuatl, 12, pp. 85-120, http:// dialnet.unirioja.es/ servlet/ articulo? codigo $=3833556$ [consultado el 29 de junio de 2017].

Nogales Rincón, David 2006. "Los espejos de príncipes en Castilla (siglos XIII-Xv): un modelo literario de la realeza bajomedieval”, Medievalismo. Boletín de la Sociedad Española de Estudios Medievales, 16, pp. 9-40, http:/ / revistas.um.es/medievalismo/article/view/50931, [consultado el 29 de junio de 2017].

Peire, Jaime 2008. "Leer la Revolución de Mayo: Bibliotecas tardocoloniales en el Río de la Plata”, Eadem Utraque Europa. Revista de Historia Cultural e Intelectual, Buenos Aires, 6, pp. 109-155.

Reyes, Alfonso 1995. Obras completas. T. 5: Historia de un siglo. Las mesas de plomo, Fondo de Cultura Económica, México.

RotTerdam, Erasmo de 1997. Los Dísticos de Catón, comentados, Universidade de Vigo, Vigo.

Ruiz Bañuls, Mónica 2005. "Vocación humanística y misión evangelizadora: los «Huehuetlahtolli» en la obra de fray Bernardino de Sahagún”, Estudios Humanísticos. Filología, 27, pp. 379-390.

Socolow, Susan M. 1978. "La burguesía comerciante de Buenos Aires en el siglo XviIı”, Desarrollo Económico, 18, 70, pp. 205-216. 
Telégrafo Mercantil: rural, político-económico e historiográfico del Río de la Plata [1 de abril al 27 de diciembre de 1801] 1914. Junta de Historia y Numismática Americana, Buenos Aires.

The Monthly Review, or, Literary Journal 1787. Vol. 76, Griffiths, London, www. books.google.com.ar [consultado el 29 de junio de 2017].

Torre Revello, José 1956. "La biblioteca de Hipólito Vieytes”, Historia, 6, pp. 72-89.

Trabulse, Elías 1988. "Clavigero, historiador de la Ilustración mexicana", en Francisco Xavier Clavigero en la Ilustración mexicana 1731-1787. Ed. Alfonso Martínez Rosales, El Colegio de México, México, http://www. cervantesvirtual.com/obra-visor/francisco-xavier-clavigero-en-la-ilustracin-mexicana-17311787-0/html/ [consultado el 29 de junio de 2017].

WAUchOPE, RoBert 1976. Handbook of middle American Indians, t. 13, University of Texas Press, Austin.

Weinberg, Gregorio 1995. Modelos educativos en la historia de América Latina, AZ Editora, Buenos Aires. 